\title{
Cultura e Mudança Organizacional: o Caso TELER]
}

\author{
Sylvia Constant Vergara \\ Mario Couto Soares Pinto
}

\section{RESUMO}

De todos os setores da economia afetados pelos efeitos das incertezas globais e pelas necessidades de mudança, um chama a atenção por seu caráter estratégico, por suas características de alta tecnologia, pela quantidade de pessoas envolvidas, pelo potencial de lucro e pelo interesse internacional: o das telecomunicações. Dentre as afiliadas da Telecomunicações Brasileiras S.A. - Telebrás está a Telecomunicações do Rio de Janeiro S.A. - Telerj, uma das mais antigas e tradicionais, além da segunda maior de todo o sistema, o que justifica a especial atenção que o presente trabalho lhe empresta. Ele busca responder até que ponto os padrões culturais da Telerj revelam a possibilidade de comportamento proativo ou, ao contrário, reativo às mudanças ambientais. Para alcançar esse objetivo, valeu-se de uma pesquisa bibliográfica e de campo, na qual foram feitas entrevistas com cerca de $25 \%$ do corpo gerencial da empresa, e foram obtidas informações adicionais através de questionários que atingiram cerca de $75 \%$ desse grupo. $\mathrm{O}$ estudo aponta uma ênfase numa cultura diretiva, onde a manutenção da ordem prevalece sobre a busca pelo novo, e conclui enumerando algumas dificuldades de adaptação da empresa.

Palavras-chaves: cultura organizacional; telecomunicações; Telerj; mudança.

\section{Abstract}

From all segments of the economy affected by the globalization uncertainty and by the needs for changing, one stays in the focus of the international concerns, because of its profit and strategical potentials: telecommunications. Among the subsidiaries of Telecomunicações Brasileiras S.A. Telebrás lays Telecomunicações do Rio de Janeiro - Telerj, one of the oldest and most important of the entire system. This paper attemtps to associate the Telerj cultural standards with its expected behavior in view of a new and hostile environment. To reach this goal, it has used a bibliographic and a field research, where about $25 \%$ of the management corps has been interwied and about $75 \%$ of this group received and answered a questionnaire.

This paper shows that the culture of Telerj is rather directive, where keeping the order is more important than creating new conditions, and concludes listing some difficulties in starting an adaptative process to succeed in the new environment.

Key words: organizational culture; telecommunications; Telerj; organizational changing. 


\section{Apresentaçāo}

O setor de telecomunicações apresenta-se como um dos mais significativos na economia mundial. Estudá-lo é, portanto, relevante. Do setor elegemos a empresa Telecomunicações do Rio de Janeiro S. A. - Telerj. Instigava-nos a vontade de verificar até que ponto seus padrões culturais revelavam a possibilidade de comportamento proativo ou, pelo contrário, reativo às mudanças ambientais que vêm ocorrendo no Brasil e no mundo.

Durante um ano - de 1995 a 1996 - ouvimos o corpo gerencial da Telerj, seja por meio de aplicação de questionários, seja em discussões em grupo ou em entrevistas individuais. Informações a respeito são fornecidas na primeira seção deste artigo.

Para alicerçar e orientar a coleta e a interpretação dos dados, a literatura sobre cultura e mudança organizacional foi revisitada, compondo a segunda seção.

A fim de contextualizar a Telerj, e sinalizar para fontes geradoras de seu estado atual, apresentamos, na terceira seção, breve histórico da empresa.

A quarta seção busca mapear a cultura da Telerj, explorando os valores mais profundos de seu quadro gerencial.

A quinta e última seção oferece a resposta à questão desencadeadora da pesquisa, bem como sugestões para nova agenda de investigações.

\section{O Problema e a Metodologia}

A preocupação com o aumento da produtividade e com a própria sobrevivência da organização em ambientes competitivos tem sido potenciada em nível mundial nos últimos anos por diversos fatores, como a globalização dos mercados, com conseqüente acirramento de concorrência, e recessão econômica, entre outros. No Brasil, em particular, essa tendência é estimulada por fatores conjunturais próprios, como a abertura do mercado local, outrora cativo, e pela ideologia da modernidade, que insiste em varrer o país para colocá-lo alinhado com o pensamento econômico neoliberal que tantos preconizam.

Para os países periféricos do capitalismo, como o Brasil, Tavares e Fiori (1993) 
observam que esse movimento nada mais representa do que uma "modernidade conservadora", filiado que está à reestruturação nos países centrais. Segundo os autores, o processo de ajuste global a que assistimos é regido pela batuta do chamado Consenso de Washington, conseqüência da finada conferência de BrettonWoods, referendado pelo Fundo Monetário Internacional e forçado pelo Banco Mundial; alcança, assim, o status de doutrina constituída e legitimada por praticamente todos os países do mundo. Observam, ainda, que os próprios países centrais não aplicam todo o receituário que recomendam aos países periféricos.

A contrapartida menos pessimista dessa situação pode ser observada pela análise de Srour (1994), que afirma estar em andamento no Primeiro Mundo um capitalismo social que valoriza a competitividade, sendo tanto integracionista como transnacional. Segundo o autor, o capitalismo brasileiro estaria afastado desta tendência, por apresentar uma essência cartorial, protecionista e oligopolista e, por isso, deve seguir adiante com as profundas reformas que ora se anunciam. Também Lodi (1993), a propósito de estudar as tendências da empresa para os anos 90, apresenta uma proposta de enxugamento, com redução de quadro, eliminação de filiais improdutivas e redução de níveis hierárquicos; é autor que se aproxima das tendências em voga nos tempos atuais.

Como se vê, qualquer que seja a matriz ideológica formatada no dorso da mudança, o que está fora de questão é que esta existe, é abrangente e gera incertezas para as organizações.

Sob esse enfoque é razoável supor que as empresas controladas pelo Estado brasileiro são as que mais têm a sofrer em termos de adaptação ao meio. Além de sentirem, tal como suas equivalentes da iniciativa privada, os efeitos das incertezas globais que o atual momento democratiza, e de terem de tratar de um emaranhado de ferramentas gerenciais que se entrelaçam em coreografia quase indecifrável, ainda têm de dar conta da mudança do antigo modelo adotado pelo Estado, que agora ameaça cortar dedos e anéis.

De todos os setores afetados, um chama a atenção por seu caráter estratégico, por suas características de alta tecnologia, pela quantidade de pessoas envolvidas, pelo potencial de lucro e pelo interesse internacional: o das telecomunicações. Dentre as afiliadas da Telecomunicações Brasileiras S.A. - Telebrás está a Telecomunicações do Rio de Janeiro S.A. - Telerj, uma das mais criticadas, que terá de arcar com parcela considerável desse processo. Sendo uma das mais antigas e tradicionais, além da segunda maior de todo o sistema, a Telerj suscita consideração e interesse, justificando a especial atenção que o presente trabalho lhe empresta. Assim, é factível supor que esta empresa pode tornar-se emblemática de um período de transformações, e a antecipação de seu comportamento diante da 
situação delineada pode tanto amenizar problemas de adaptação, como suavizar traumas neste grupo e nos que a ele certamente se seguirão.

Enfocada a Telerj, o estudo concentrou-se no seu nível gerencial, que alcançava na época da investigação 1388 pessoas de um universo total de cerca de 14000 funcionários. Entendemos que esse grupo detém o poder institucional de facilitar ou não o processo de adaptação à nova realidade.

Não foi incluído no estudo o segmento do corpo diretor que, na época da pesquisa, não possuía um passado em comum com o grupo. As pessoas desse segmento, de rápida passagem por tal posição, circulavam nela de acordo com critérios de nomeação, normalmente político-partidários, configurando-se claramente num grupo à parte.

A pesquisa de campo foi realizada em três fases. Na primeira, foram aplicados questionários aos diversos níveis gerenciais. Foram atingidos 684 gerentes, ou seja, aproximadamente metade do universo, embora válidos tenham sido considerados 536 questionários. Na segunda fase também foram aplicados questionários, mas a eles seguiram-se discussões em grupo com os respondentes. Foram atingidos mais 300 gerentes, ou seja, cerca de $22 \%$ do universo. Cada grupo tinha em média 20 pessoas, as quais, voluntariamente e avisadas do objetivo daquele encontro, deram seus depoimentos. Dentro de cada grupo havia certa homogeneidade de nível hierárquico, mais nítida no início dos trabalhos, relaxando no seu decorrer. A terceira fase da pesquisa de campo expressou-se em entrevistas realizadas com 14 pessoas percebidas como relevantes no processo de investigação.

O questionário foi composto por dez perguntas, cada uma contendo cinco afirmações, identificadas de A a E. Cada uma dessas opções deveria ser pontuada de um a cinco, de acordo com sua menor ou maior adequação com aquilo que o participante entendia ser a Telerj, não podendo ser repetido o mesmo grau dentro do mesmo conjunto de afirmações. Cada pergunta privilegiou um tema específico dentre as múltiplas possibilidades que compõem uma organização produtiva: os tópicos iam desde a obtenção de resultados e lucros até a questões mais afeitas ao trato humano, como a criatividade e o controle. Cada uma das cinco afirmações formatava a empresa em molde distinto, o seu ambiente. $O$ resultado da ponderação das notas atribuídas pelo participante às dez questões acabava por enquadrar a empresa em um ambiente, entendido este como seu perfil, conforme será discutido mais adiante.

$\mathrm{Na}$ primeira fase da pesquisa apenas tabularam-se os dados. Na segunda, os resultados já tabulados foram discutidos e interpretados com os participantes, numa tentativa de expor os números alcançados ao crivo da experiência vivida por cada grupo. Cada elemento dispunha de ampla liberdade para concordar ou 
não com o apresentado, mas era nítido o consenso, ao fim de poucos minutos de discussão. Nesse momento, eram obtidos dados preciosos sobre o passado da empresa, normalmente não constantes de qualquer manual impresso, e outros elementos não argüidos formalmente pelo questionário. Dessa forma, foi possível perceber e demarcar os heróis da Telerj, seus rituais e alguns eventos importantes, que ficaram registrados na memória do grupo.

Além desse trabalho coletivo, foram realizadas entrevistas individuais com elementos-chaves da empresa. Essas ocorreram no próprio ambiente de trabalho do entrevistado e almejavam debater pontos específicos ainda não suficientemente esclarecidos.

As respostas dos questionários foram segmentadas por nível gerencial, da seguinte maneira: o primeiro grupo foi composto de gerentes que ocupam a parte mais elevada da pirâmide gerencial da empresa (190 pessoas); o segundo, representando os gerentes situados na faixa intermediária da hierarquia (314 pessoas); e o terceiro grupo, com os diversos tipos de supervisores, base do corpo gerencial da Telerj (480 pessoas). O resultado de cada subgrupo foi comparado com o resultado do grupo inteiro, com o objetivo de identificar possíveis microculturas alimentadas por diferentes posturas hierárquicas.

Os comentários feitos pelos grupos por ocasião da discussão do questionário, e por indivíduos nas entrevistas, foram confrontados com os resultados obtidos no questionário, dando ao conjunto uma consistência interna que formou a base para um mapeamento mais aprofundado da cultura da Telerj.

Aos dados obtidos no campo foram acrescentadas declarações publicadas de executivos, comunicados internos, organogramas, dados obtidos no Museu do Telefone e outros.

\section{ReVISITANDO A Literatura}

\section{O Interesse na Cultura da Organização Produtiva}

Até a década de 70 as propostas de mudança dentro do ambiente organizacional, com vistas a responder a variações ambientais ou a estratégias de crescimento, mostravam-se vinculadas à visão clássica, funcionalista e comportamentalista da empresa, com alteração de organogramas e trocas de pessoal. No entanto, a partir dos anos 80 , vem sendo constatado que a falta de entendimento mais completo, holístico e multifacetado da empresa inviabilizou várias tentativas e esforços de transformação organizacional. Assiste-se, ainda hoje, à emergência de opções te- 
órico-práticas, as quais são lançadas em seqüência, numa tentativa desesperada de amenizar os efeitos de ambiente tão instável.

Refletindo sobre essas opções, no entanto, observa-se que a maioria delas é devedora em algum nível da parte encoberta, privada da lógica racional a que nos acostumamos, que compõe o todo da identidade e da ação de um grupo. A rigor, é exatamente o que está abaixo do imediatamente observável que irá intimidar a abordagem tayloro-fordista da organização, e que, se não for tratado convenientemente, inviabilizará tanto as propostas de mudança como a própria estabilidade. Conforme assevera Fleury (1992), as características objetivas mostram-se incapazes de explicar muitos dos processos organizacionais, especialmente aqueles envolvidos com mudanças, conflitos e reações. A dinâmica social do grupo é regida por fatores que tanto podem facilitar como dificultar um processo de mudança, podendo explicar tanto o sucesso como o fracasso de uma adaptação necessária (ou imposta, tanto faz), como as conseqüências desta para o próprio grupo. $\mathrm{O}$ aspecto cultural de uma empresa vem tratar do muito de subjetividade existente nas organizações e do qual as ferramentas tradicionais não conseguem dar conta.

Dentre os possíveis motivos percebidos por Aktouf(1994), que explicam esse aumento das preocupações com o tema, estaria, em primeiro lugar, a própria globalização, que forçou a gerência americana a se deparar com o outro. Essa aldeia global rasgou em parte o etnocentrismo que o autor entende ser característica daquela sociedade. Sem dúvida, o sucesso da economia japonesa ao longo da década de 80 e o declínio relativo da economia americana nesse período foram elementos motivadores para a busca imediata de respostas. O segundo ponto seria a constatação de um deslocamento das teorias da organização e de comunicação, especialmente na última década, que passaram a preocupar-se com os complexos determinantes mentais do comportamento humano. Um terceiro aspecto complementa o anterior, quando a mudança de rumo da administração desaguou na preocupação com significações subjetivas, desviando-se do caminho tradicional que se apegava às explicações objetivas dos fenômenos organizacionais, atestando certa fragilidade do modelo racional e científico.

\section{Definindo Cultura no Âmbito da Organização}

Como fez com outros ramos do conhecimento, a administração adotou da sociologia e da antropologia o conceito de cultura. Por causa disso, esse termo traz uma assinatura que faz com que extrapole os limites da organização produtiva e da própria administração. Para Aktouf (1994, p. 41), por exemplo, "a utilização do termo cultura [é] uma espécie de empréstimo do termo, sem que se pretenda 'importar' tudo aquilo de que ele está carregado, quando localizado no seu con- 
texto de origem". Assim, a aplicação do termo no ambiente empresarial seria uma redução arbitrária. Afinal, rodízio elevado de pessoal, imposições gerenciais e inadequação entre objetivos pessoais e empresariais são elementos que ameaçam o caráter de autoconstituição que o conceito sugere em seu contexto inicial.

Por outro lado, Fleury (1992) reconhece que o termo dispõe de roupagem específica, quando aplicado às peculiaridades de uma organização produtiva, agregando padrões psicológicos, políticos e sociais. Devido a essa aglutinação de enfoques, a autora entende que o conceito está numa fase de elaboração que confere simultaneidade às definições de conteúdo e forma. O que utilizamos conceitualmente seria uma "bricolage de elementos teóricos e empíricos" (Fleury, 1992, p. 10).

Por sua vez, Schein (1992) trata o termo dentro da linha de aprendizagem do grupo diante das realidades percebidas. Serão as explicações compartilhadas pelo grupo em face da sua experiência vivida que tecerão os laços entre os homens. As respostas aprendidas levarão, obrigatoriamente, a valores, e esses a comportamentos, sem que seja possível uma avaliação consciente de sua origem. Em última instância, o grupo é ensinado sobre o que é ou não correto, e norteará sua ação a partir daí. Para esse autor existem três formas diferentes de o grupo desenvolver, aprender e expressar sua cultura. A primeira, superficial e facilmente observável, diz respeito aos artefatos visíveis, tais como lay-out e organogramas. A segunda envolve os valores conscientes e compartilhados do grupo. Esses já são mais difíceis de serem observados diretamente, sendo necessário um trabalho de abordagem dos membros da organização; estes contudo expressarão apenas os elementos manifestos. A última forma trata dos pressupostos inconscientes, que formam um plano fundamental de imanência de valores para o indivíduo e para o grupo, afetando tanto sua relação com o ambiente como sua crença na natureza humana.

Santos (1994) introduz uma conotação repressiva e direcionadora no conceito, que funcionaria como mecanismo de controle, informalmente aprovando ou proibindo comportamentos dos membros da organização. Por essa ótica, a cultura do grupo atua como elemento restritivo, capaz de dificultar processos de mudança, devido a um clamor coletivo por estabilidade. Em última instância, a resistência à mudança é um movimento inerente ao grupo na sua tentativa de preservar os padrões de comportamento já testados.

\section{Mudança e Resistência à Mudança}

Talvez não exista tema mais antigo e mais atual do que mudança. Dos filósofos antigos, a partir de Heráclito, era comum a idéia de que a única coisa que não muda é que tudo muda. Suspeitava Arendt (1992) que o fio da tradição se esticara 
tanto, que acabou por romper-se. Para a administração, ponta de lança do homo faber, é fundamental a existência de mecanismos que amorteçam o impacto das mudanças, antecipando cenários que possibilitem uma correta tomada prévia de decisão. Dentro dessa tônica, vemos inúmeras propostas que tratam da adequação da empresa às excentricidades do meio, tais como a reengenharia, qualidade total, administração estratégica e tantas outras, conforme nos esclarece Pereira (1994).

Qualquer que seja a orientação, não é possível à organização testar um processo de mudanças sem a contrapartida de sua transformação cultural, dentro da participação e do comprometimento do grupo como um todo, conforme afirma Frenzel (1993). Sob esse aspecto, a visão de Moscovici (1988) nos esclarece de que a tentativa unilateral de mudança de uma cultura, sem que haja a preocupação em ajustá-la à realidade organizacional em que se insere, tem sido um exercício vão, que habitualmente gera perda de recursos e de credibilidade a seus líderes. A mudança cultural precisa, então, ser sustentada por formas que não sejam estranhas à organização, para que haja real motivação e comprometimento com seus objetivos. Afirma ainda que, independentemente de as ameaças oriundas da percepção da mudança pelo grupo serem imaginárias ou não, seus efeitos são sempre reais e se manifestam na resistência que o grupo impõe ao processo.

Essa afirmação remete-nos a outro impasse, que trata da possibilidade ou não da alteração planejada da cultura de uma organização. Pettigrew (1992) responde-nos à pergunta-título de seu ensaio com um sonoro sim, enquanto Aktouf (1994, p. 47), por outro lado, encontra nessa afirmativa claros "odores manipulativos", acrescentando que tal situação "faz crer que a cultura possa ser alguma coisa diferente da realidade vivida, espontânea, subjetiva dos indivíduos [...] para ser alguma coisa que possa ser decretada e mudada à vontade". Mais adiante, esse autor chama de "demiurgos" os executores de tal tentativa. Vale, então, observar o comentário de Freitas (1991), que associa a atribuição básica do administrador, que é a de imputar maior grau de previsibilidade à organização que lidera, à imutabilidade da cultura. Reconhecê-la como tal, assevera a autora, seria aceitar que o sucesso ou fracasso de uma empresa estaria sob o comando de elementos imprevisíveis e incontroláveis. De qualquer forma, um projeto forçado de mudança organizacional pode vir a desestabilizar um grupo, visto que "os símbolos que são criados para dar sentido à vida, e que são uma forma de manifestação desse sentido, são quebrados, negados ou substituídos" (Freitas, 1991, p. 120). 


\section{A Telerj e o Ambiente}

\section{Da Invençăo do Telefone à Situaçăo Atual da Telerj}

Um dado interessante da história da Telerj é a facilidade com que podemos relacionar a empresa com o invento. Em 1876, ano em que o telefone foi pela primeira vez mostrado ao público em uma exposição, na Filadélfia, EUA, Dom Pedro II, em visita àquele país, solicitou e recebeu do próprio Graham Bell, de quem já ouvira falar anteriormente, uma demonstração particular. No ano seguinte já havia um telefone instalado no Rio de Janeiro, ligando o Corpo de Bombeiros à casa comercial $\mathrm{O}$ Grande Mágico, e outro ligando a firma Fernando Rodde \& Cia à Bolsa de Valores; e em 1878, várias outras conexões particulares já eram postas a funcionar (Ruiz, 1973). Em 13 de outubro de 1880, era criada em Boston, EUA, a Companhia Telefônica do Brasil, subsidária da Continental Telephone Company, que no ano seguinte seria autorizada pelo Imperador a atuar no Brasil. Dessa maneira, foi introduzido o serviço no Brasil, sob a administração de uma empresa estrangeira e a posse do Governo.

Dessa época até 1920, aproximadamente, a história do serviço telefônico no Brasil passou por grandes e freqüentes alterações, com seguidas criações de empresas, encampações, associações, fusões, trocas de nomes e de donos e até da forma como o serviço se estruturava. De permanente ficava a exploração do serviço por empresas estrangeiras, a maioria americanas, mas também alemãs e canadenses que se sucediam mutuamente. Em 1916, a empresa canadense Brazilian Traction criou The Rio de Janeiro and São Paulo Telephone Company, para desenvolver as atividades telefônicas do grupo. Essa empresa mudou seu nome em 1923 para Brazilian Telephone Company, sendo chamada, facultativamente no Brasil, de Companhia Telephonica Brasileira - CTB, que se consolidou daí em diante sob a rígida administração americana, usando materiais, métodos e normas próprios, alguns resistindo até os dias atuais. Em 1956, foi nacionalizada no Governo de Juscelino Kubitschek, alterando sua ortografia para Companhia Telefônica Brasileira e transferindo sua sede de Toronto para o Rio de Janeiro.

Nesse tempo, a CTB já possuía subsidiárias em Minas Gerais e no Espírito Santo, e dispunha de mais de 700.000 terminais. A partir da década de 60 passou a aparecer com constância a palavra crise em seus relatórios, que mostravam um crescimento na demanda por novas linhas praticamente igual ao número de telefones já existentes, e que não conseguia ser suprido pela empresa (Ruiz, 1973). Em 1960, o Governo do Estado da Guanabara realizou uma intervenção no serviço local da CTB, que perdurou até o ano seguinte, quando a Assembléia Legislativa fez surgir uma nova empresa, a Companhia Estadual de Telefones - Cetel, que 
ficaria responsável pela telefonia da Zona Rural e das Ilhas do Estado da Guanabara. Em 1962, nova intervenção ocorreu na CTB, agora de iniciativa do Governo Federal, que entregou a direção da empresa a militares de sua confiança, normalmente coronéis ou generais. Essa intervenção continuou até a Revolução de 1964, que pôs em prática a política de nacionalização e unificação dos serviços telefônicos do país.

Em 1971, a Companhia Telefônica de Minas Gerais - CTMG, futura Telecomunicações de Minas Gerais - Telemig, e a Companhia Telefônica do Espírito Santo - CTES ganharam autonomia e desligaram-se da CTB; em 1973, foi a vez de ser criada a Telecomunicações de São Paulo - Telesp, ficando a CTB limitada a atuar nos Estados da Guanabara e do Rio de Janeiro, juntamente com a Cetel. Finalmente em 22 de fevereiro de 1976, foi criada a Telecomunicações do Rio de Janeiro S.A. - Telerj.

Um momento relevante na história da Telerj foi a encampação da Cetel, ocorrida no final da década de 80 . Essa empresa, com um contingente aproximado de um décimo da Telerj, tinha procedimentos significativamente distintos, e sua absorção foi vista com certa desconfiança pela anfitriã, pouco afeita a diferenças. Até hoje, quase uma década depois, é observável a separação entre cetelinos e telerjianos, cada qual valorizando suas particularidades.

Nos dias correntes, configura-se um horizonte pouco tranqüilo à empresa: além das questões financeiras, convive com forte pressão veiculada na mídia, que ressalva a baixa qualidade dos serviços que presta à população. Numa pesquisa recente, publicada no jornal O Globo de 22 de dezembro de 1995, a Telerj aparece no topo da lista de insatisfação do consumidor de serviços públicos, retendo para si mais de $40 \%$ do total de reclamações. Essa situação não se alterou de forma significativa em 1997.

Quanto às propostas efetivas que redesenharão o antigo monopólio, essas ainda não estão claras para o Governo e para sua base parlamentar; certamente terão o perfil que as negociações políticas, ora em andamento, permitirem. Existem várias especulações circulando na imprensa, o que dá um alto grau de indefinição para o futuro do setor. De concreto existem as fartas declarações do Ministro das Comunicações, ratificadas pelos projetos e portarias preliminares enviados ao Congresso em 28 de novembro de 1995, que apontam para o agrupamento das 27 empresas subsidiárias da Telebrás em " 5 ou 6 Babybrás", que misturariam empresas maiores com outras de menor porte, como as do Norte do país. Até o momento, foram contabilizadas dezenas de emendas ao projeto do Ministro, enviadas por vários deputados federais de diferentes partidos.

Com um quadro tão confuso, poucas são as certezas de que as empresas do 
setor dispõem, o que abre espaço para uma ansiedade profunda e, em alguns casos, paralisante.

\section{Mapeando a Cultura da Telerj}

\section{O Questionário Aplicado}

Conforme pode ser visualizado na Tabela 1, o tempo médio de casa dos respondentes é alto (mais de 20 anos), como relativamente alto é o tempo médio na função, variando entre cerca de 4 e 8 anos, apesar da maior dispersão neste caso.

\section{Tabela 1: Estatísticas de Tempo de Casa e de Função (valores expressos em anos)}

\begin{tabular}{|l|ll|ll|ll|ll|}
\hline Estatística & Tempo & Tempo & Tempo & Tempo & Tempo & Tempo & Tempo & Tempo \\
& Casa & Fnção & Casa & Fnção & Casa & Fnção & Casa & Fnção \\
(todos) & (todos) & (ger sup) & (ger sup) & (ger med) & (ger med) & (ger inf) & (ger inf) \\
\hline Média & 21,18 & 7,36 & 20,93 & 4,55 & 21,32 & 7,60 & 21,14 & 8,34 \\
Ds. Padrão & 5,2 & 6,28 & 5,58 & 4,90 & 4,93 & 6,54 & 5,22 & 6,24 \\
Cf Var (\%) & 24,54 & 85,3 & 26,65 & 111,70 & 23,10 & 86,07 & 24,72 & 74,85 \\
$\mathbf{1}^{\circ}$ Quartil & 18 & 2 & 18 & 1,48 & 18 & 2 & 18 & 3 \\
Mediana $^{2}$ & 21 & 5 & 21 & 2,63 & 21 & 5 & 21 & 5 \\
$\mathbf{3}^{\circ}$ Quartil & 25 & 11 & 24 & 6,25 & 25 & 13 & 25 & 13 \\
Moda & 20 & 2 & 23 & 2 & 20 & 2 & 19 & 3 \\
\hline
\end{tabular}

No questionário, o grupo ordenava em importância quatro aspectos da organização que o presente trabalho considerou relevantes, a saber: o espírito de equipe, $o$ ambiente diretivo, o ambiente protetor e $o$ ambiente neutro, e ainda classificava a empresa quanto à sua mobilidade e flexibilidade. Entendemos que esses quatro ambientes, arbitrariamente escolhidos, dizem respeito a todas as organizações, mas não as esgotam. Vale ressaltar que os quatro enfoques adotados, caso sejam analisados individualmente, esvaziam-se de significado, enquanto sua visão inter- 
ligada funciona como fotografia panorâmica, ainda que simplificada, de como os funcionários percebem e sentem a empresa.

$\mathrm{Na}$ organização definida como ambiente diretivo existe uma restrita participação dos subordinados nas decisões tomadas pela cúpula que, na maioria dos casos, não se preocupa em mantê-los informados de objetivos ou estratégias. Também não existe espaço para maiores questionamentos, o que, conjugado à concentração de poder no topo da hierarquia, pode acentuar os contornos políticos da organização, em detrimento da valorização de critérios de competência. Se existir, o descontentamento não é exposto frontalmente, mas de forma dissimulada, devido à precariedade dos canais de comunicação e ao temor de punições. Nesse ambiente nenhum esforço de delegação vai além do discurso.

De espírito de equipe chamamos o aspecto da empresa que valoriza a contribuição individual para o bem comum, havendo forte sentimento de identificação da parte com o todo, e vice-versa, de forma que os objetivos individuais e do grupo são compartilhados.

Já uma organização mais nitidamente enquadrada sob o enfoque de ambiente protetor consagra uma forte preocupação com as relações interpessoais, patrocinando um processo de pacificação constante. O controle, que normalmente é fonte de atritos, ou não é exercido ou o é de forma indireta e mediada.

O ambiente neutro está associado ao enfoque técnico da organização e às tarefas que compõem seu cotidiano. Ao contrário do lugar onde prevalece o ambiente protetor, numa empresa onde predomina a neutralidade as relações interpessoais não ocupam o centro das preocupações, sendo freqüente o trabalho isolado, a pouca visão global e o desinteresse pela política. Cada funcionário mostra-se mais envolvido com seus afazeres técnicos e com os seus pares mais próximos do que com a empresa como um todo.

O último aspecto, mobilidade e flexibilidade, diz respeito à capacidade da organização em resistir ou adaptar-se às flutuações do ambiente. No que se refere à cultura, esse item indica o quanto a organização é capaz de olhar para o ambiente, perceber a necessidade de mudança e manejar suas próprias competências para reorganizar-se.

\section{Análise dos Resultados}

A principal característica dos dados coletados por meio dos questionários é a homogeneidade das respostas. Seja observando toda a amostra, considerando as 836 respostas válidas, no total das 984 fornecidas, como pode ser sinalizado na Tabela 2, seja segmentando-a nos três níveis hierárquicos estudados, como sinte- 
tizam as Tabelas 3, 4 e 5, a distribuição estatística dos pontos é extremamente semelhante. Vale ressaltar que tanto as médias como os desvios-padrões, modas e medianas, de todos os cinco itens analisados estão próximos entre si. Em alguns desses itens, a maior oscilação percebida ficou inferior a 5\%, como visto nos ambiente diretivo e protetor, sendo que, no último, a maior diferença entre os grupos só despontou nas casas decimais. Por outro lado, salta aos olhos, também, a grande heterogeneidade entre os três níveis hierárquicos, tanto em nível salarial, como em escolaridade, o que, associado à significativa dispersão temporal, de mais de um ano, separando o primeiro grupo que respondeu ao questionário do último que o fez, valoriza ainda mais a semelhança das respostas.

Tabela 2: Estatísticas, considerando toda a Amostra da Telerj

\begin{tabular}{|l|l|l|l|l|l|}
\hline Estatísticas & Amb Diretivo & Amb Protetor & Amb Neutro & Espírito Eq. & Mobil/Flexib \\
\hline Média & 34,75 & 27,41 & 32,36 & 23,64 & 31,77 \\
Ds. Padrão & 5,68 & 4,57 & 6,25 & 7,24 & 4,07 \\
Cf. Variação (\%) & 16,31 & 16,67 & 19,31 & 30,23 & 12,83 \\
$\mathbf{1}^{\circ}$ Quartil & 31 & 24 & 28 & 18 & 29 \\
Mediana & 35 & 27 & 32 & 23 & 32 \\
$\mathbf{3}^{\circ}$ Quartil & 39 & 30 & 37 & 28,75 & 34,75 \\
Moda & 36 & 26 & 36 & 18 & 31 \\
\hline
\end{tabular}

Tabela 3: Estatísticas, considerando apenas os Gerentes de Nível Superior na Hierarquia

\begin{tabular}{|l|l|l|l|l|l|}
\hline Estatísticas & Amb Diretivo & Amb Protetor & Amb Neutro & Espírito Eq. & Mobil/Flexib \\
\hline Média & 34,68 & 27,19 & 33,1 & 22,69 & 32,34 \\
Ds. Padrão & 4,84 & 4,10 & 6,29 & 6,47 & 4,09 \\
Cf. Variação (\%) & 15,40 & 15,86 & 18,66 & 30,38 & 12,07 \\
$\mathbf{1}^{\circ}$ Quartil & 31 & 24 & 30 & 17 & 30 \\
Mediana & 35 & 27 & 34,5 & 22 & 32 \\
$\mathbf{3}^{\circ}$ Quartil & 39 & 30 & 38 & 26 & 35 \\
Moda & 36 & 27 & 37 & 18 & 31 \\
\hline
\end{tabular}




\section{Tabela 4: Estatísticas, considerando apenas os Gerentes no Nível Intermediário}

\begin{tabular}{|l|l|l|l|l|l|}
\hline Estatísticas & Amb Diretivo & Amb Protetor & Amb Neutro & Espírito Eq. & Mobil/Flexib \\
\hline Média & 35,53 & 26,9 & 34 & 21,56 & 32,04 \\
Ds. Padrão & 5,27 & 4,22 & 6,04 & 6,79 & 3,67 \\
Cf. Variação (\%) & 14,83 & 15,68 & 17,77 & 31,49 & 11,45 \\
$\mathbf{1}^{\circ}$ Quartil & 32 & 24 & 30 & 17 & 29 \\
Mediana & 36 & 27 & 35 & 20 & 32 \\
$\mathbf{3}^{\circ}$ Quartil & 39 & 30 & 38 & 25 & 34 \\
Moda & 36 & 27 & 36 & 18 & 33 \\
\hline
\end{tabular}

Tabela 5: Estatísticas, considerando apenas os Gerentes da Base da Hierarquia

\begin{tabular}{|l|l|l|l|l|l|}
\hline Estatísticas & Amb Diretivo & Amb Protetor & Amb Neutro & Espírito Eq. & Mobil/Flexib \\
\hline Média & 34,37 & 27,90 & 30,75 & 25,60 & 31,38 \\
Ds. Padrão & 6,03 & 4,85 & 5,99 & 7,22 & 4,37 \\
Cf. Variação (\%) & 17,55 & 17,39 & 19,47 & 28,41 & 13,92 \\
$\mathbf{1}^{\circ}$ Quartil & 31 & 25 & 27 & 20 & 29 \\
Mediana & 35 & 28 & 31 & 25 & 32 \\
$\mathbf{3}^{\circ}$ Quartil & 39 & 31 & 35 & 30 & 34 \\
Moda & 36 & 26 & 34 & 25 & 34 \\
\hline
\end{tabular}

O fato de essa visão ser compartilhada com tanta veemência por todos os níveis gerenciais da Telerj reforça a idéia de que existe um padrão de comportamento bem definido, monolítico, fortemente sedimentado, que perpassa integralmente o segmento gestor da empresa. Utilizando a definição de Schein (1988), estaria aí construída uma ligação entre o nível comportamental, relativo aos valores do grupo, e o dos pressupostos inconscientes, os quais formam a cultura propriamente dita. 
Dessa forma, parece-nos que, no caso da Telerj, existe um exercício quase secular, conforme apresentamos no histórico da empresa, de uma valorização da ordem, da hierarquia e da disciplina, que lhe confere um aspecto estrutural significativamente semelhante ao da rigidez militar. Interferências no conjunto foram, e continuam sendo, fortemente desestimuladas, o que sugere uma verticalização profunda dos padrões de comportamento tradicionalmente aceitos. O novo, o que irrompe, deve ser abortado em tempo hábil, porquanto ameaça o statu quo, que redime e garante a estabilidade. A movimentação e a mudança, quando inevitáveis, apresentam-se, dialeticamente, apenas para assegurar a conformidade; mudase $o$ artefatual para que os paradigmas sejam preservados. A balança pende mais para a rigidez do que para a adaptabilidade e, como tal, o risco de ruptura no caso de tentativas de deslocamentos ou mudanças de rota não deve ser descartado.

Atentando para os números alcançados nos questionários, é possível traçar um perfil médio do telerjiano, que serviu como ponto de partida para as considerações feitas por meio de outros instrumentos de pesquisa. Afora o profundo enraizamento de que a cultura da Telerj demonstra dispor, observamos um peso significativo no eixo diretividade-neutralidade, com clara predominância do primeiro. Todavia, mesmo admitindo que os ambientes diretivo e neutro formam o modus operandi de nossa sociedade, é fácil observar a utilização, por parte das empresas, de inúmeros mecanismos de mediação: estes abrandam uma situação que, quando posta a nu, é no mais das vezes insustentável. A rigor, existem várias ferramentas à disposição e em uso pelas organizações, tanto para mascarar razões que não devem ser expostas, como para otimizar o funcionamento da empresa. Pagès (1987) descreve com detalhes alguns desses mecanismos na TLTX.

A Telerj, no entanto, parece prescindir de exercer tal mediação, fazendo com que a natureza das relações entre os funcionários, e desses com a empresa, possa aparecer com grande clareza. Não existe esforço em amenizar ou ocultar qualquer diretividade, conforme o depoimento dos entrevistados; em vez de tratar-se de um descuido gerencial, entendemos que esse desprendimento é expressão manifesta de aspectos inconscientes da cultura Telerj, que se apresenta credora de um padrão profundamente arraigado de não-contestação e de valorização do único. Essa visão chapada e unidirecional da realidade transita sem constrangimentos numa ambiência de força capaz de proteger o grupo de qualquer ameaça à estabilidade. A energia, o mando e a obediência dão vida ao braço forte que sustenta e determina, e oferecem a (improvável) escolha entre ordem e caos.

Toda a energia não direcionada para o questionamento indesejável é naturalmente sublimada para o viés mais introspectivo, no sentido não-político descrito por Arendt (1992), que forma o ambiente neutro. Existe, assim, uma harmonia entre o não-falar e o fazer técnico, um reforçando o outro, exatamente de acordo 
com características descritas do animal laborans. É razoável admitir a existência de grandes quantidades de pequenas ilhas isoladas umas das outras, mas interligadas umbilicalmente a um ponto central, que as abastece com os direcionamentos desejados. A baixa pontuação recebida pelo espírito de equipe é emblemática da previsibilidade que percorre a cultura da Telerj, e que é uma de suas principais particularidades; afinal, para um espaço onde ladeiam a extrema diretividade e a neutralidade, nada mais adequado e profético do que a ausência da empatia e da noção do conjunto. Pelos números alcançados neste tópico, associados aos dos dois itens anteriores, não seria impossível prever significativas dificuldades para a empresa levar adiante projetos de gestão participativa, ou outra idéia que pressuponha o envolvimento ativo dos funcionários.

O quarto aspecto que completa o panorama é a posição sem viço do ambiente protetor, situado bem atrás do ambiente neutro e bem na frente do espírito de equipe. Não obstante seu apagado terceiro lugar, entendemos que essa característica adequa-se perfeitamente a um ambiente que teme o conflito e preserva a cordialidade. Assim, não se espera de um gerente da Telerj uma atitude agressiva com relação a seus pares: ao contrário da TLTX de Pagès (1987), a ambição nessa organização não ocupa posição tão central e é vista com certa desconfiança pelo grupo. Afinal, existe uma ordem que não pode ser desautorizada e regras que devem ser respeitadas. Já a relação do grupo com a empresa, e vice-versa, pressupõe um certo assistencialismo, cujo benefício é mais dado de cima para baixo do que conquistado.

O último aspecto que o questionário aborda é o da mobilidade e flexibilidade; o item que apresentou menor variabilidade entre todos os cinco tópicos analisados, cerca de $12 \%$, e menor desvio-padrão, tem sido também o elemento mais semelhante entre as três microculturas em estudo, ou seja, as referentes aos níveis gerenciais. Essas características conferiram às respectivas curvas normais um formato análogo, todas de perfil bem alto e estreito. Tamanha proximidade de resultados reforça, uma vez mais, o aspecto uniforme da cultura da Telerj, mesmo entre os diferentes estratos hierárquicos. A rigor, nesse item, onde poderíamos imaginar que a experiência funcional de cada subgrupo pudesse causar maior variação, é justamente o que menor dispersão apresenta. Tal fato pode ser interpretado como uma predominância dos aspectos mais profundos, não-racionais, da cultura sobre aqueles associados à cognição. Em outras palavras, mesmo que o topo da pirâmide hierárquica seja o responsável em perceber a necessidade de mudança e em promovê-las, e na prática dispõe de meios racionais efetivos para cumprir ambas as tarefas, compartilha dos mesmos filtros paradigmáticos dos níveis hierárquicos inferiores, deles não se diferenciando.

No processo de discussão das respostas aos questionários, a postura dos diver- 
sos grupos foi muito semelhante quando os resultados de todos eram tabulados no quadro, não demonstrando nenhuma surpresa com os números obtidos, com os quais concordavam. Era comum nos grupos que compunham as gerências intermediária e imediata a seguinte pergunta: "Nas turmas dos gerentes de departamento os resultados são os mesmos?". Diante da resposta afirmativa, parecia haver certa decepção, como se a redenção esperada por todos estivesse um pouco mais longe. Nos componentes da gerência superior não foi percebido nenhum desconforto. Eles, porém, apontavam razões de ordem estrutural, normalmente políticas ou históricas, para justificar os números obtidos. Assim, podemos observar uma tendência dos níveis hierárquicos inferiores de delegarem para o alto as responsabilidades sobre os destinos da empresa. São "os de cima", e apenas eles, que devem criar as condições para que "os de baixo" possam trabalhar corretamente e para que a empresa venha a florescer. Os do alto, por não terem mais a quem delegar, atribuem à situação atual (e futura) a certa naturalização das circunstâncias, contra o que muito pouco pode ser feito. Assim, há um misto de resignação e impotência, que é comum a todos os níveis, cada qual com suas explicações particulares.

Foram comuns as alusões à face política da Telerj, o que, para o grupo, vem carregado de conotações desairosas. Segundo os participantes, da diretoria para cima, entenda-se presidência e ministérios da área, estão todos muito pouco preocupados com os destinos da empresa, utilizando-a apenas como trampolim para suas carreiras políticas. Essa visão é tão mais forte quanto mais descemos na hierarquia, e refere-se a praticamente toda a história da empresa. Vale ressaltar que há certa apropriação, sem limites claros, do que é considerado como sendo político. Para esse termo vale tanto a atividade partidária, seja da direção da empresa, seja do sindicato, como a discussão para encaminhamento de questões inerentes à atividade-razão da empresa, passando também pela conduta mais subserviente que "um ou outro colega" adota para obter vantagens. Em todos esses sentidos, o teor é sempre pejorativo, o que se ajusta no perfil mais neutro da organização. Afinal, como o uso da palavra é um pré-requisito do elemento político, se este é tido como danoso, nada mais razoável do que a obediência à norma fria, do ponto de vista técnico, e a pouca atividade comunicativa, dando tons enfáticos à diretividade.

Um bom exemplo é o da porta da esperança, numa alusão a um programa de televisão em que o apresentador atende, paternalisticamente, a pedidos de seus convidados. Esse fato ocorreu numa gestão recente: o presidente da empresa recebia os funcionários em sua sala e atendia a seus pedidos, aparentemente, sem maiores reflexões sobre as conseqüências. Então, pessoas que pleiteavam transferências para outras áreas ou localidades, por exemplo, recebiam um faça-se como resposta, e o assunto estava encerrado. Tal fato sugere uma predominância do 
aspecto político sobre o funcional na organização, o que só é possível em ambientes de regras não muito claras, no que se refere à gestão estratégica, e uma voz de comando imperativa, diante da qual se dobram tanto as pessoas como a própria razão de ser da empresa.

Outro fato recente, ocorrido em fins de 1994, é bastante significativo e diz respeito à promoção do grupo. No que pareceu ser uma tentativa de inaugurar uma gestão participativa, foi dada aos funcionários a incumbência de se analisarem mutuamente, de acordo com critérios pré-estabelecidos, de forma que se definisse uma classificação que facilitaria a promoção dos melhores. Assim, dentro de cada setor, cerca de 10 a 20 pessoas, o grupo pontuaria cada um, ficando o gerente com a missão de corrigir desvios. O que se afigurava como processo de modernização administrativa, acabou trazendo muitas dificuldades. O projeto foi levado adiante e as promoções ocorreram, acarretando muitas distorções, visto que alguns grupos deram nota máxima para todos seus integrantes. Para tentar corrigi-las, entrou em campo a conhecida diretividade, acompanhada pelo ambiente protetor, e foi dada pela empresa a ordem para que todos os que não tivessem sido promovidos nos últimos 24 meses o fossem automaticamente, o que foi imediatamente cumprido.

Essa história é rica em significados. Primeiro, descortina a confusão esperada quando os funcionários são instados a tomarem em suas mãos seus próprios destinos. Em segundo lugar, observamos a forma como o processo foi encaminhado, partindo de uma decisão do alto da pirâmide hierárquica. Aliás, da mesma forma como foi iniciado, o caminho foi interrompido de cima para baixo, com a interferência da empresa, que marcou sua posição de força e apaziguou descontentamentos. Com isso, a dor do aprendizado, que a primeira vez normalmente obriga, foi em vão, e ao grupo só coube reforçar o lado negativo da tentativa, o que já será um débito a ser pago por futuras empreitadas. $\mathrm{O}$ terceiro ponto refere-se à fórmula encontrada, que desautoriza qualquer iniciativa de diferenciação entre os funcionários. A despeito dos inúmeros problemas apresentados, o processo tinha como mérito justamente a constatação da existência do outro, mas se todos são tão iguais é porque não existe o limite que tanto separa como protege. Por último, temos uma vez mais a priorização de aspectos não diretamente funcionais sobre os relativos ao desempenho da empresa, pois um processo de promoção acabou transformando-se num aumento generalizado de salário, sem qualquer vínculo com aumento de produtividade.

Até aqui foi possível pontuar algumas formas de expressão da predominância do aspecto diretivo da cultura da empresa. As ações do grupo estão intimamente relacionadas com o mote "manda quem pode, obedece quem tem juízo", que surgiu com grande freqüência ao longo das discussões em grupo, e que por si só já 
sintetizaria toda a exposição. Veremos que também os heróis da Telerj confirmam esse ponto. O principal nome lembrado, até com certo saudosismo, por quase todos os grupos era o de um presidente da empresa nos anos 80 . Sobre ele disseram: "Esse, sim, defendeu a empresa. Se tinha um problema, ele ia a Brasília e resolvia na hora"; "Podia ser quem fosse que ele não levava desaforo para casa"; "Ele é que deu condições para a empresa operar. Ele pressurizou a rede e fez as obras de infra-estrutra que garantem o funcionamento da empresa até hoje. Depois dele ninguém fez mais nada"; "Ele pensava no funcionário. Criou o clube, deu seguro saúde e vários outros benefícios que agora estão querendo tirar"; "Ele era festeiro".

Esse perfil é representativo da diretividade e da proteção, pois ele "defende a empresa [até] em Brasília". Lembra o pai que não deixa desamparados os filhos, defendendo-os da injustiça e da politicagem, e garantindo aos oprimidos e ameaçados sua pacífica existência. Ele dá e protege; logo ninguém precisa partir para a conquista ou afrontar a estabilidade.

\section{Conclusões e Sugestóes}

A orientação adotada pelo presente trabalho aponta para uma interferência essencial de aspectos subjetivos nos caminhos e metas que determinada organização abraça. A explicação científica, fíliada a uma genealogia cartesiana, mostra pouca competência ao alongar seu confortável conhecimento natural aos motivos humanos, o que nos faz refletir sobre a existência de uma ideologia que impõe uma realidade única, prenhe de conceitos lineares e positivos. Encontramos na cultura a conexão entre o verbo e o ato, entre o opaco e o transparente, que movimenta, dialeticamente, os atores da organização produtiva; foi essa convicção que nos indicou as rotas de busca dentro do universo telerjiano.

Os caminhos trilhados para delimitar os contornos desse espectro mostraram-se surpreendentemente afinados; tatearam os valores do grupo gerencial da empresa que, entendemos, dispõe da autorização formal de aglutinar e conduzir o todo. Os resultados obtidos no questionário apresentaram confiabilidade; os obtidos nas discussões grupais e nas entrevistas, bem mais sutis, assentaram a anterior com significativa adequação, o que sugere que, pelo menos do ponto de vista adotado, existe um razoável grau de segurança quanto ao perfil encontrado.

Duas características presentes na cultura da Telerj foram marcantes; acreditamos não ser possível a compreensão da empresa, em qualquer nível, sem sua devida consideração. A primeira, evidenciada nos resultados do questionário, apon- 
ta para uma fantástica homogeneização do grupo, que conserva crenças e posturas extremamente semelhantes, independentemente da segmentação de que ele seja objeto. Entendemos esse efeito como uma verticalização aprofundada da cultura da empresa; qualquer tentativa de mudança deverá, obrigatoriamente, levar em consideração esse forte enraizamento. O segundo ponto diz respeito a uma diretividade intensa, que tanto cimenta a existência do grupo, como confere o alcance e o tom de sua ação. Essa face é tão imperiosa, que outros aspectos thes são devedores, tais como o sentido paternalista de proteção e o entrincheiramento técnico. Em conjunto, esses braços reforçam-se mutuamente e definem o que pode ou não ser feito e pensado na Telerj.

Apesar do cuidado de não enveredarmos por convenientes relações de causalidade, que empobrecem a possibilidade de interação humana, entendemos que esses aspectos estruturais da cultura da empresa foram reforçados por toda sua história, repleta de intervenções, condução militar e subordinação estratégica a uma ideologia totalizante. Também seu herói-fundador, figura mais facilmente identificável em empresas privadas, pode ser creditado à CTB, empresa quase secular e possuidora de um passado altamente regulador e impositivo.

Com todo esse peso pressionando o homem da Telerj ao longo de décadas, e com o confortável afastamento do novo e da exterioridade, houve uma modelagem de seu perfil que passou a valorizar a cordialidade e a docilidade, e a excluir a disputa e o conflito. Existe uma busca por relações harmoniosas entre pares e com a organização, que desemboca numa previsibilidade e estabilidade que renegam a diferença. Surge, então, um viés paternalista que é expressado na preocupação do telerjiano com sua segurança e com outros fatores higiênicos, e na sua certeza de que a empresa nunca lhe negará abrigo. Dessa forma, estão estabelecidas as condições para um assistencialismo indissociável da diretividade, capaz de acalmar qualquer desconforto passageiro.

A preocupação com o lado técnico, largamente citada ao longo da pesquisa, parece ser uma adequação do grupo ao acento diretivo que lhe é imposto, e que está repleto de indesejáveis colorações políticas. $O$ vazio surgido com a execração do que o grupo entende como político é satisfatoriamente preenchido com seu oposto, o neutro. Seu exercício prescinde do esforço comunicativo, e os feudos de iguais podem formar-se livremente. Paralelamente, o espírito de equipe do todo fica comprometido, devido à existência de uma prática de isolamento tribal, que empresta surpreendente similaridade à suposta dessemelhança. Essa pacata essência poderia prolongar-se indefinidamente, se o ambiente não se insurgisse tão repentina e violentamente, com os momentos de glória que o liberalismo comemora atualmente no mundo. As mudanças em andamento no Estado brasileiro quebram quaisquer garantias existentes, e denunciam o contrato de não-agressão do qual o grupo aparece signatário. 
Quanto à questão principal da pesquisa, ou seja, até que ponto os padrões culturais da Telerj revelam um comportamento proativo ou, pelo contrário, reativo às mudanças ambientais, concluímos que existe um bem delineado perfil cultural de negação à diferença, o que acaba por constranger a mudança nessa organização. Como as condições atuais são diferentes daquelas que historicamente a empresa vivenciou, o fato de esse comportamento emergir com força de proposta única, se não for contornado a tempo, acabará por colocar a Telerj em desconfortável posição num futuro próximo. Entendemos que a maior dificuldade identificada é a falta de conhecimento das regras da disputa, e em quanto tempo essa ocorrerá. Uma mudança dessa monta, num grupo desse porte, não se completa de uma hora para outra e, devido à rigidez de sua cultura, o respeito ao timing do grupo será fundamental para sua preservação.

No entanto encontramos indícios de que o grupo percebe a significativa alteração ambiental em andamento; já existem focos dispostos a se comprometer em processo adaptativo mas, no momento, não temos ainda condições de avaliar suas possibilidades de êxito. A adaptação passará, certamente, pela palavra, essa desconhecida, e somente seu enfático incremento pode fazer romper décadas de obediência ensimesmada. Mediante a discussão em várias direções, explodindo a clássica abordagem vertical adotada, será possível a constatação das diferenças e das limitações do grupo.

Como continuidade dessa investigação, sugerimos uma verificação do que o grupo entende ser adequado para superar esses momentos difíceis. Tal pesquisa pode indicar com maior exatidão quais os paradigmas culturais do grupo que deverão ser enfrentados, bem como auxiliar na pavimentação de caminhos que levem a empresa a um porto seguro. Também ficou pouco claro, no presente trabalho, o estágio de conscientização em que o grupo se encontra face às ameaças que o cercam. Essa certificação associa-se à anterior, e facilitaria sobremaneira o planejamento de uma inevitável alteração de perfil cultural. Outra continuação interessante seria procurar associar os valores da empresa aos da sociedade brasileira, aproximando a pesquisa de uma abordagem sociológica. Além de resgatar um débito que o tema apresenta com essa área, possibilitaria melhor aferição do alcance das raízes culturais da empresa, facilitando a elaboração de estratégia de adaptação mais precisa. 


\section{ReferénCias Bibliográficas}

AKTOUF, O.

O simbolismo e a cultura de empresa : dos abusos conceituais às lições empíricas. In: CHANLAT, J. F. $O$ indivíduo na organizacão - dimensões esquecidas. São Paulo: Atlas, 1994. v. 2.

ARENDT, $\mathrm{H}$.

Entre o passado e o futuro. São Paulo : Perspectiva, 1992.

FLEURY, M. T. L.

O desvendar a cultura de uma organização - uma discussão metodológica. In: FLEURY, M. T. L.; FISCHER, R. M. (Orgs). Cultura e poder nas organizações. São Paulo : Atlas, 1992.

FREITAS, M. E.

Cultura organizacional : formação, tipologias e impacto. São Paulo : Makron, 1991.

FRENZEL, R.

Uma reflexão sobre processos de mudança organizacional. In: XVII ENCONTRO ANUAL DA ANPAD (1993 : Salvador). Anais ... Salvador : ANPAD, 1993. v. 9.

LODI, J. B.

A nova empresa para os anos 90 - lições da década perdida. São Paulo : Pioneira, 1993.

MOSCOVICI, F.

Renascença organizacional. Rio de Janeiro : Livros Técnicos e Científicos, 1988.

\section{PAGÈS, M.}

$O$ poder das organizações. São Paulo : Pioneira, 1987.
PEREIRA, M. J. L. DE B.

Modelos de mudança nas organizações brasileiras : uma análise crítica In: BJUR, W.; CARAVANTES, G. R. Reengenharia ou readministração? Porto Alegre : AGE, 1994.

PETTIGREW, A. M.

A cultura das organizações é administrável? In: FLEURY, M. T. L.; FISCHER, R. M. (Orgs). Cultura e poder nas organizações. São Paulo : Atlas, 1992.

RUIZ, R.

O Telefone. Rio de Janeiro : Gráfica Danúbio, 1973.

SANTOS, N. M. B. F.

Diagnosticando a cultura organizacional através da abordagem tipológica de Quinn : uma pesquisa nas empresas brasileiras do setor têxtil. In: XVIII ENCONTRO ANUAL DA ANPAD (1994 : Curitiba). Anais ... Curitiba : ANPAD, 1994. v. 10.

SCHEIN, E.

Organizational culture and leadership. San Francisco : Jossey-Bass, 1992.

SROUR, R. H.

Formas de gestão : o desafio da mudança. Revista de Administração de Empresas, jul./ago., 1994.

TAVARES, M. DA C.; FIORI, J. L.

Desajuste global. Rio de Janeiro : Paz e Terra, 1993. 